\title{
Pequenas Moléculas que Mudaram a Síntese Assimétrica
}

O Prémio Nobel da Química de 2021 foi atribuído a Benjamin List (Max-Planck-Institut für Kohlenforschung, Mülheim an der Ruhr, Alemanha) e David MacMillan (Princeton University, EUA). 0 prémio foi anunciado pela Real Academia Sueca das Ciências no passado dia 6 de outubro, e distinguiu os cientistas pelo "desenvolvimento da organocatálise assimétrica". Na natureza as enzimas catalisam inúmeras reações químicas, construindo moléculas essenciais à vida. Os organocatalisadores são pequenas moléculas puramente orgânicas, e constituídas essencialmente por átomos de carbono, hidrogénio, oxigénio, nitrogénio, enxofre e fósforo. 0 uso de organocatalisadores constitui uma forma de imitar a natureza, ou seja, a catálise enzimática. Até ao ano 2000 a maior parte dos catalisadores aplicados na síntese enantiosseletiva consistiam essencialmente em enzimas ou catalisadores metálicos. A organocatálise veio revolucionar a forma de sintetizar moléculas, em diversos domínios, desde a síntese de produtos naturais à descoberta de fármacos. Os contributos de List e MacMillan revêem-se na expressão que Primo Levi apresenta no seu livro A tabela periódica: "Químicos: os transformadores de matéria".

Mais detalhes sobre a história da organocatálise, cuja linha cronológica é apresentada na imagem, serão desvendados no próximo número do QUíMICA.

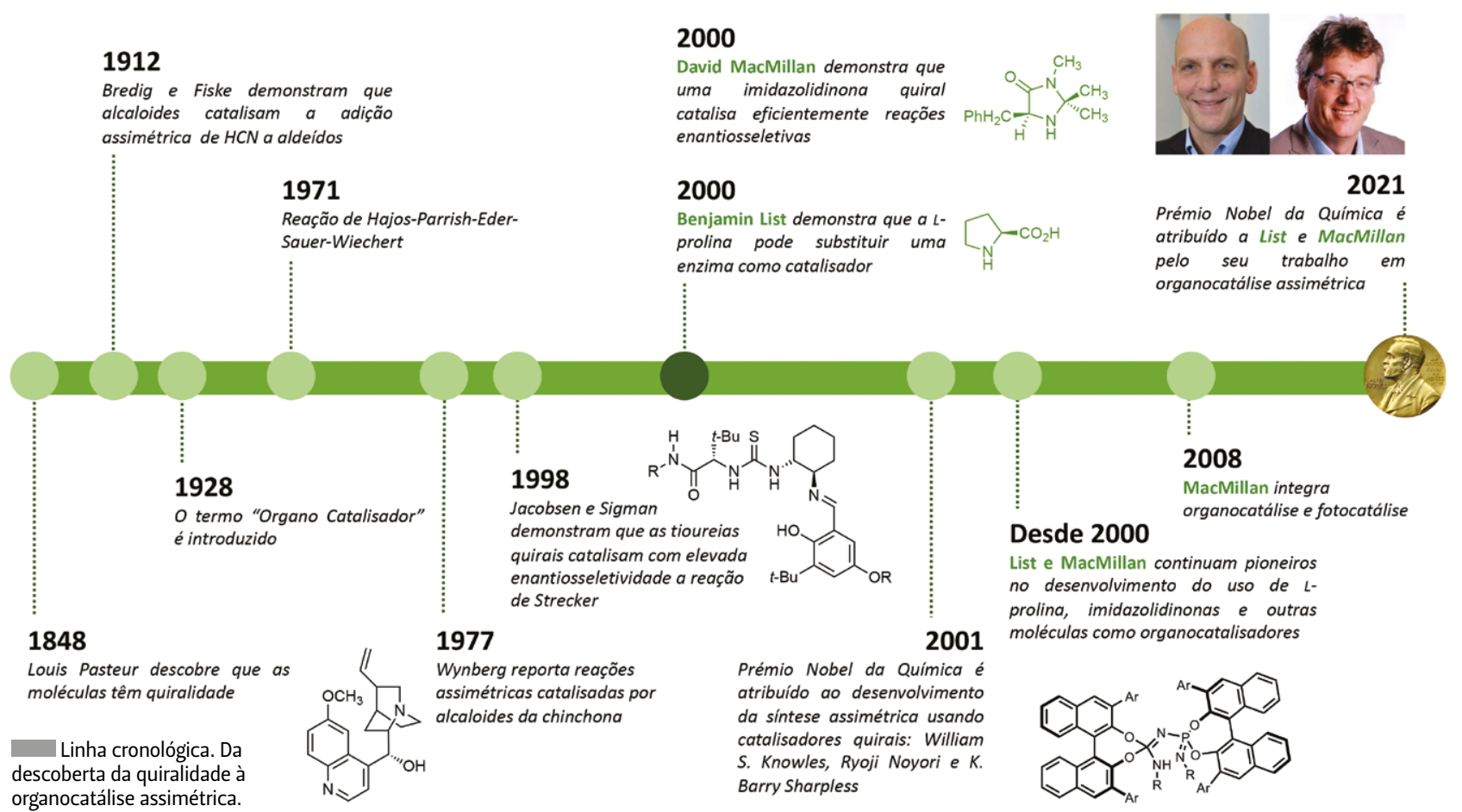

Benjamin List nasceu em Frankfurt, Alemanha, em 1968. Estudou química na Free University of Berlin e obteve o grau de mestre em 1993. Em 1997 obteve o grau de doutor na Goethe University Frankfurt, sob a orientação do Professor Johann Mulzer. Entre 1997 e 1998 esteve a desenvolver trabalho de investigação de pós-doutoramento nos Estados Unidos, no Scripps Research Institute, no departamento de Biologia Molecular em La Jolla, com uma bolsa da Fundação Alexander von Humboldt. Durante este tempo, trabalhou no grupo de Carlos F.
Barbas III e Richard Lerner. Entre 1999 e 2003, foi professor auxiliar no mesmo instituto. Em 2003 voltou para a Alemanha como líder de grupo no Max-Planck Institute for Coal Research, liderando o departamento de Catálise Homogénea em 2005. No período de 2012 a 2014 , foi diretor do mesmo instituto. List é ainda, desde 2004, professor honorário de química orgânica da Universidade de Colónia. É investigador principal do Institute for Chemical Reaction Design and Discovery - Hokkaido University, desde 2018. É editor de revistas científicas, tais como a Synlett. Em 2021 foi-lhe atribuído o Prémio Nobel da Química.

David MacMillan nasceu em Bellshill, Escócia, em 1968. Estudou na Universidade de Glasgow, onde obteve o bacharelato em 1991. Em 1996, obteve o grau de doutor na Universidade da Califórnia em Irvine, sob a orientação de Larry Overman. Realizou os seus estudos de pós-doutoramento com David A. Evans na Universidade de Harvard. A partir de 1998 esteve na Universidade da Califórnia em Berkeley e, a partir de 2000 , no California Institute of Technology, onde se tornou professor em 2004. Desde 2006 é professor da Universidade de Princeton. É fellow da Royal Society, desde 2012, e em 2004, recebeu a Medalha Corday-Morgan da Royal Society of Chemistry. É membro da Academia de Artes e Ciências dos Estados Unidos. Em 2015 recebeu o Prémio Ernst Schering. Desde 2010 é editor da revista Chemical Science. Em 2021 foi-Ihe atribuído o Prémio Nobel da Química.

\section{Manuel B. Marques \\ msbm@fct.unl.pt}

